University of South Carolina

Scholar Commons

6-1-2007

\title{
Adaptive Control Strategy for Active Power Sharing in Hybrid Fuel Cell/Battery Power Sources
}

Zhenhua Jiang

University of Miami, zjiang1@miami.edu

Lijun Gao

Boeing, Lijun.gao@boeing.com

Roger A. Dougal

University of South Carolina - Columbia, dougal@engr.sc.edu

Follow this and additional works at: https://scholarcommons.sc.edu/elct_facpub

Part of the Electrical and Computer Engineering Commons

Publication Info

Published in IEEE Transactions on Energy Conversion, Volume 22, 2007, pages 507-515.

http://ieeexplore.ieee.org/xpl/Recentlssue.jsp?punumber=60

(C) 2007 by IEEE

This Article is brought to you by the Electrical Engineering, Department of at Scholar Commons. It has been accepted for inclusion in Faculty Publications by an authorized administrator of Scholar Commons. For more information, please contact digres@mailbox.sc.edu. 


\title{
Adaptive Control Strategy for Active Power Sharing in Hybrid Fuel Cell/Battery Power Sources
}

\author{
Zhenhua Jiang, Member, IEEE, Lijun Gao, Member, IEEE, and Roger A. Dougal, Sr. Member, IEEE
}

\begin{abstract}
Hybrid systems composed of fuel cells and batteries combine the high energy density of fuel cells with the high power density of batteries. A dc/dc power converter is placed between the fuel cell and the battery to balance the power flow between them and greatly increase the peak output power of the hybrid. This paper presents an adaptive control strategy for active power sharing in the hybrid power source. This control strategy can adjust the output current setpoint of the fuel cell according to the state-of-charge (or voltage) of the battery, and is applicable in two topologies of active fuel cell/battery hybrids. The control strategy is implemented in Simulink and then tested under arbitrary load conditions through simulation and experiments. Simulation and experimental results show that the adaptive control strategy is able to adjust the fuel cell output current to adapt to the charge state of the battery, and appropriately distribute the electrical power between the fuel cell and the battery. Experiments demonstrate the generality of the adaptive control strategy.
\end{abstract}

Index Terms-Active power sharing, adaptive control strategy, battery, fuel cell, hybrid power sources, power converter.

\section{NOMENCLATURE}

\begin{tabular}{|c|c|}
\hline$A_{\text {cell }}$ & Area of each cell $\left(\mathrm{cm}^{2}\right)$ \\
\hline$b, r, m$, and $n$ & $\begin{array}{l}\text { Polynomials determined empirically from } \\
\text { experimental data. }\end{array}$ \\
\hline$E_{0}$ & Standard potential of $\mathrm{H}_{2}-\mathrm{O}_{2}$ reaction $(\mathrm{V})$. \\
\hline$I_{b}$ & Charging current to the battery $(\mathrm{A})$. \\
\hline$I_{\mathrm{fc}}$ & Output current from the fuel cell stack (A). \\
\hline$I_{\mathrm{mpp}}$ & $\begin{array}{l}\text { Current of the fuel cell corresponding to the } \\
\text { maximum power point (A). }\end{array}$ \\
\hline$I_{\text {meff }}$ & $\begin{array}{l}\text { Current of the fuel cell corresponding to the } \\
\text { maximum efficiency point (A). }\end{array}$ \\
\hline$I_{r b}$ & Battery charging current setpoint (A). \\
\hline $\mathrm{rfc}$ & Fuel cell current setpoint (A). \\
\hline$N_{\text {cell }}$ & $\begin{array}{l}\text { Series number of the cells in the fuel cell } \\
\text { stack. }\end{array}$ \\
\hline$P_{\mathrm{fc}}$ & $\begin{array}{l}\text { Output electrical power of the PEM fuel cell } \\
\text { stack (W). }\end{array}$ \\
\hline$V_{b}$ & Battery voltage $(\mathrm{V})$ \\
\hline$V_{\mathrm{bmin}}$ & $\begin{array}{l}\text { Battery low voltage disconnection setpoint } \\
(\mathrm{V}) \text {. }\end{array}$ \\
\hline$V_{r b}$ & Battery voltage setpoint $(\mathrm{V})$ \\
\hline$\Delta G_{\mathrm{T}}$ & $\begin{array}{l}\text { Change in free energy of the electrochemical } \\
\text { oxidation of the fuel }(\mathrm{J}) \text {. }\end{array}$ \\
\hline
\end{tabular}

Manuscript received December 29, 2003; revised February 1, 2005. Paper no. TEC-00371-2003.

Z. Jiang is with the Department of Electrical and Computer Engineering, University of Miami, Coral Gables, FL 33146 USA (e-mail: zjiangl@miami.edu).

L. Gao and R. A. Dougal are with the Department of Electrical Engineering, University of South Carolina, Columbia, SC 29208 USA (e-mail: gaolijun@ engr.sc.edu; dougal@engr.sc.edu).

Digital Object Identifier 10.1109/TEC.2005.853747

$\begin{array}{ll}\Delta H_{0} & \begin{array}{l}\text { Enthalpy change for the total oxidation reac- } \\ \text { tion of the fuel (J). }\end{array} \\ \eta_{\max } & \begin{array}{l}\text { Maximum theoretical efficiency of the fuel } \\ \text { cell. }\end{array} \\ \text { SOC } & \text { State-of-charge of the battery. }\end{array}$

\section{INTRODUCTION}

C LEAN and convenient energy is becoming more and more attractive in industrial and commercial applications at a variety of power levels. Modern handheld electronic devices such as PDAs, cellular phones, portable computers, camcorders, MEMS, and radios have fueled a great need for new highenergy, small-volume portable power supplies [1]. New generations of electric vehicles or airplanes may require lightweight power sources having high power density [2], [3]. Current technology batteries by themselves are insufficient to provide the long-term power (energy between refuelings) that these systems require. Fuel cells of reasonable size may provide the necessary energy, but cannot (economically) provide the high peak power occasionally demanded by these systems. Hybrid power sources composed of fuel cells and batteries combine the high power density of batteries with the high energy density of fuel cells [4], [7]. Furthermore, a fuel cell-battery hybrid system enables instant cold-start operation since the battery meets the majority of the load demand while the fuel cell is warming up, and allows both components to be of smaller dimensions and to operate with higher efficiency, since neither has to provide the full load and capacity.

The passive hybrid that results from connecting both the fuel cell and the battery directly to the power bus [4], allows less flexibility in the system design compared to the active hybrid. This is because the nominal voltages of the fuel cell stack and the battery must be similar in order to not overcharge the battery, yet the similar voltages then determine in a rather fixed way the amount of power that can be supplied from the fuel cell to the battery or to the load. Therefore, as an alternative to the passive hybrid, a dc/dc power converter can be placed between the fuel cell and the battery so that the power sharing between the two components can then be actively controlled, which greatly increases the peak output power [5]. A major issue arising in design of the hybrid power source is the algorithms for control of the power sharing. The study described in [6] deals with control strategies based on two distinct and conflicting objectives: either maximizing fuel cell output power or maximizing the efficiency of the fuel cell source. With the former strategy, the battery would eventually become fully charged but the efficiency would not be maximized while, with the latter strategy, the fuel cell would achieve maximum efficiency, but the battery would finally 


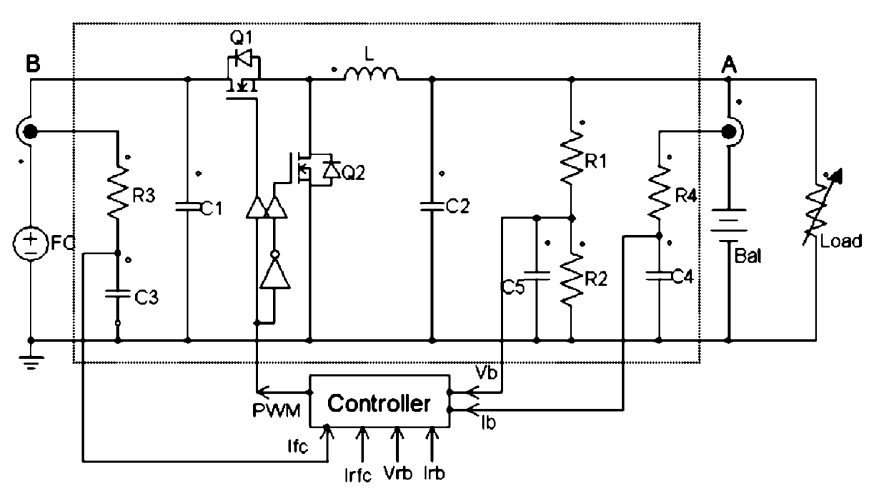

Fig. 1. Simplified circuit diagram for the active hybrid fuel cell/battery power source.

run down to depletion. The objective of this study is thus to achieve a strategy that embodies the very best properties of each of these two strategies, with none of the detrimental properties.

This paper presents an adaptive control strategy for active power sharing in the hybrid power source. The control strategy can adjust the output current setpoint of the fuel cell according to the charge level (voltage) of the battery, and is applicable in two different configurations of the active hybrids. The control strategy is implemented in Simulink and then tested under arbitrary load conditions through simulation and experiments. The results validate the capability of the adaptive control strategy for adjusting the fuel cell output current to adapt to the charge state of the battery, and for efficiently distributing the electrical power demand between them.

\section{Active Power Sharing IN Hybrid POWER SOURCES}

Fig. 1 schematically shows the simplified circuit diagram of one configuration of an active hybrid fuel cell/battery power source (Configuration I). The load is directly connected to the battery at node A. The fuel cell is connected to both the battery and the load through a dc/dc step-down converter. The battery provides additional power when the load needs high power and is charged by the fuel cell when the load demand is low. Current transducers sense the currents from the fuel cell and into the battery. Resistors R1 and R2 form a voltage divider to measure the battery voltage. The measured fuel cell current, battery current, and battery voltage are input to the controller. The voltage and current limits of the battery are set by $V_{r b}$ and $I_{r b}$, respectively. The controller sets the fuel cell current reference $I_{\mathrm{rfc}}$ continuously according to the battery charge level. The controller also calculates the duty cycle and produces a continuous PWM drive signal for the buck converter. In Fig. 1, connecting the load to the fuel cell at node B (rather than to the battery at node A) results in another configuration of the hybrid power source which we term Configuration II.

The electrical power output and the overall efficiency are two important indicators of the performance of the power source. Since the power available from the fuel cell stack is limited, it may sometimes necessary to operate the fuel cell at its maximum power point. The empirical equation given in (1) is often used to describe the electrical power output of a PEM fuel cell stack [8]

$$
\begin{aligned}
P_{\mathrm{fc}}=N_{\text {cell }} \cdot\left[E_{0}\right. & -b \cdot \log \left(\frac{I_{\mathrm{fc}}}{A_{\text {cell }}}\right) \\
& \left.-r \cdot \frac{I_{\mathrm{fc}}}{A_{\text {cell }}}-m \cdot \exp \left(n \cdot \frac{I_{\mathrm{fc}}}{A_{\text {cell }}}\right)\right] \cdot I_{\mathrm{fc}}
\end{aligned}
$$

where $P_{\mathrm{fc}}$ is the electrical power output of the PEM fuel cell stack (W), $E_{0}$ the standard potential of the $\mathrm{H}_{2}-\mathrm{O}_{2}$ reaction $(\mathrm{V})$, $I_{\text {fc }}$ the output current from the fuel cell stack (A), $N_{\text {cell }}$ the series number of the cells, $A_{\text {cell }}$ the area of each cell $\left(\mathrm{cm}^{2}\right)$, and $b, r, m$, and $n$ are polynomials determined empirically from experiment data. It is clear from (1) that the output electrical power $P_{\mathrm{fc}}$ reaches the maximum point when $\partial P_{\mathrm{fc}} / \partial I_{\mathrm{fc}}=0$. In other words, when the output current of the fuel cell stack is some certain value, say $I_{\mathrm{mpp}}$, the fuel cell achieves the maximum output electrical power.

The ideal efficiency of a fuel cell considered by itself has a maximum theoretical value $\eta_{\max }$ at zero delivered power, given by

$$
\eta_{\max }=\frac{\Delta G_{T}}{\Delta H_{0}}
$$

where $\Delta G_{\mathrm{T}}$ is the change in free energy of the electrochemical oxidation of the fuel $(\mathrm{J})$, and $\Delta H_{0}$ the enthalpy change for the total oxidation reaction of the fuel (J). However, considering the entire fuel cell system, which includes parasitic losses from equipment such as pumps, fans, blowers, heat exchangers, and the electronic control system, the practical efficiency of the fuel cell system may be quite different from the theoretical value. It will depend on the system selected, the operating conditions (i.e., temperature, pressure, and fuel used), and also on the system specific technical components and balance of plant (BOP) solutions. A contribution to the understanding of fuel cell system efficiency and operation under full and part load is presented in [9]. In practical operation, the maximum efficiency point will occur somewhere other than (and obviously less than) the maximum power point. We will call this maximum efficiency point $I_{\text {meff }}$.

Since operating the fuel cell power source at its maximum power point produces poor energy efficiency, and operating at the maximum efficiency point does not produce rated power [6], we seek instead to regulate the fuel cell current on a continuously varying basis in response to the load power demand. An adaptive strategy for doing this is presented in Section III.

\section{AdAPTIVE CONTROL StRATEGy FOR ACtive POWER SHARING}

\section{A. Adaptive Control Strategy}

In general, the hybrid power source is optimized so that the fuel cell provides the energy required by the load, while the battery supports the peak power demands of the load. Over time, the battery may occasionally run down to depletion or up to full charge. Since the state-of-charge of the battery indicates its potential to meet peak power demands, our adaptive control strategy adjusts the output current of the fuel cell according to the charge level of the battery. Whenever the battery charge 


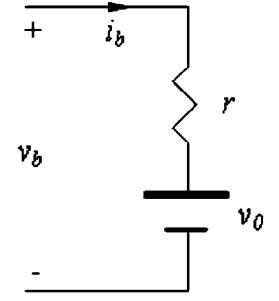

Fig. 2. Illustration of the equivalent circuit of the battery as it is connected to a voltage bus.

level exceeds $80 \%$, the fuel cell operates at maximum efficiency mode to save fuel. If the battery charge drops below $40 \%$, the fuel cell operates at the maximum power mode, providing more power to the load or charging the battery at a higher current. When the battery charge level is between $40 \%$ and $80 \%$ full, the fuel cell current is regulated on a continuous basis, proportional to the battery depth-of-discharge which is calculated as unity minus state-of-charge. The control strategy is explained in (3)

$I_{\mathrm{rfc}}= \begin{cases}I_{\mathrm{meff}}, & \mathrm{SOC} \geq 0.8 \\ I_{\mathrm{meff}}+\frac{0.8-\mathrm{SOC}}{0.4}\left(I_{\mathrm{mpp}}-I_{\mathrm{meff}}\right), & 0.4<\mathrm{SOC}<0.8 \\ I_{\mathrm{mpp}}, & \mathrm{SOC} \leq 0.4\end{cases}$

where $I_{\mathrm{rfc}}$ is the fuel cell current setpoint, and SOC the stateof-charge of the battery.

It is currently impossible to measure battery state-of-charge directly. However, for the lithium-ion batteries that are of interest to this application, there exists an approximately linear relationship between the state-of-charge and open-circuit voltage, when the state-of-charge is not within the extreme ranges [10] (the range of interest here is from $40 \%$ to $80 \%$ ). The fuel cell current can therefore be decided according to the open-circuit voltage, which is given in (4)

$$
I_{\mathrm{rfc}}= \begin{cases}I_{\mathrm{meff}}, & v_{o} \geq v_{1} \\ I_{\mathrm{meff}}+\frac{v_{1}-v_{o}}{v_{1}-v_{2}}\left(I_{\mathrm{mpp}}-I_{\mathrm{meff}}\right), & v_{2}<v_{o}<v_{1} \\ I_{\mathrm{mpp}}, & v_{o} \leq v_{2}\end{cases}
$$

where $v_{o}$ is the battery open-circuit voltage, values of $v_{1}$ and $v_{2}$, respectively, correspond to $80 \%$ and $40 \%$ state-of-charge and can be obtained by measuring the open-circuit voltage when charging the battery to $80 \%$ and $40 \%$ full, where the stateof-charge is decided using the following approach [10]. Each battery is discharged to full depletion. A constant current is then applied to charge the battery until it is full and the total charging time is recorded. After fully depleting this battery, charging this battery with the same current for a proportion (equal to the state-of-charge in magnitude) of the total charging time can approximately obtain a desired state-of-charge.

It is impossible to directly measure the open-circuit voltage when the battery is connected to a loaded distribution bus, so we use the simple equivalent circuit of the battery as illustrated in Fig. 2. It is obvious that the relation between the terminal voltage $v_{b}$ and the open-circuit voltage $v_{0}$ can be described by (5)

$$
v_{b}=v_{o}+i_{b} \cdot r
$$

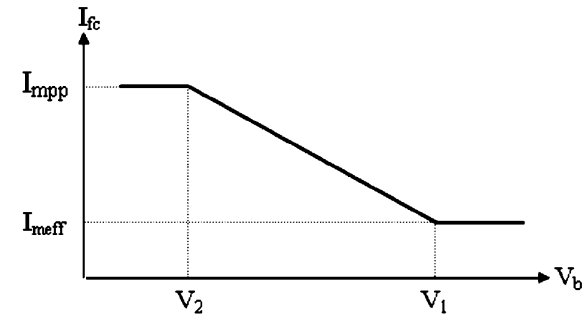

Fig. 3. Modified strategy for the fuel cell current setpoint that is decided by the battery terminal voltage.

where $i_{b}$ is the current flowing into the battery (negative if the current flows out from the battery), and $r$ is the equivalent series resistance (ESR) of the battery. (While much more sophisticated models of the battery can also be used, such models have a negligible impact in this application.)

In the practical operation, the strategy shown in (4) can be modified by substituting the measured battery voltage $v_{b}$ for the open-circuit voltage $v_{0}$ for two reasons. First, this modification eliminates the need for obtaining information of the battery open-circuit voltage. Second, the term of internal voltage-drop (corresponding to the equivalent series resistance-ESR) has a self-adaptive capability for a change in the load. When the load demand is relatively low, the fuel cell may charge the battery at a higher rate. In this case, the battery terminal voltage is higher than the open-circuit voltage. The modified strategy will set a smaller fuel cell current than that using the open-circuit voltage, which results in fuel savings. When the load needs high power, the battery will discharge. In this case, the battery terminal voltage is lower than the open-circuit voltage. The modified strategy will get a larger fuel cell current than that using the open-circuit voltage, which compensates for the increase in the load.

The modified strategy is illustrated in Fig. 3. When the battery terminal voltage exceeds an upper-limit $\left(v_{1}\right)$, the fuel cell current is regulated at $\mathrm{I}_{\text {meff }}$. When the terminal voltage is below a lower limit $\left(v_{2}\right)$, the fuel cell current is regulated at $\mathrm{I}_{\mathrm{mpp}}$. When the terminal voltage is between $v_{1}$ and $v_{2}$, the fuel cell current is regulated in reverse proportion to the terminal voltage.

The control strategy must regulate the fuel cell current while limiting either the charging current or the voltage of the battery as appropriate. Respecting these limits is especially critical for advanced technology batteries such as lithium-ion. Only the duty cycle of the power converter can be controlled. By changing the duty cycle, the output current of the fuel cell, and the voltage or current of the battery can be regulated, but not independently. Thus, there are three regulation modes: fuel cell current limit (FCCL) mode, battery current limit (BCL) mode, and battery voltage limit (BVL) mode, each based on different goals. In the hybrid power source, the battery terminal voltage is an important index for the regulation mode. When the battery terminal voltage is below the limit voltage, which may correspond to the condition of a heavy load or a light load coupled with low battery charge, then either the fuel cell current or the battery current is limited, depending on the load. If the load demand is very high, the battery may be discharged or charged at a lower rate (lower 


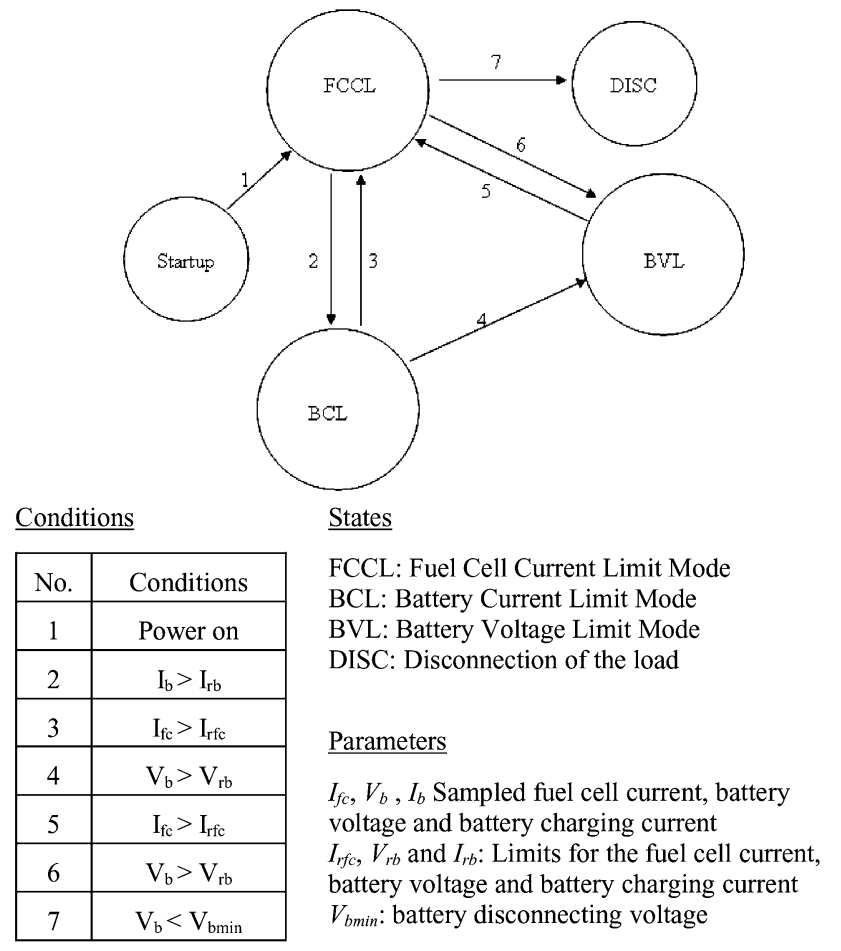

Fig. 4. State machine representation of the adaptive control strategy for fuel cell/battery hybrid power sources.

than the limit). Then fuel cell current limit mode applies and the fuel cell current depends continuously on the battery terminal voltage according to the modified strategy. If the current demand makes the output current of the fuel cell lower than the current reference calculated according to the voltage of the battery, the charging current of the battery may need to be regulated in order to protect the battery; i.e., battery current limit mode applies. In this case, the fuel cell current is unregulated but is always below its limit. When the battery terminal voltage exceeds the voltage limit, which may correspond to the condition of no load or a light load as well as high battery charge, then battery voltage limit mode must apply to prevent overcharging the battery. Under this mode, the output current of the fuel cell and the charging current of the battery should be below the limit currents. Fig. 4 shows the state machine representation of the control strategy. The circles represent the regulation modes (states) of the system. The arrows indicate the changes from one regulation mode to another (events). Each event happens under a corresponding condition that is unique to the present regulation mode. The conditions of state transitions are summarized in the table of Fig. 4.

\section{B. Simulink Implementation of Adaptive Control Strategy}

MATLAB/Simulink is selected as the tool for the control system design for two reasons. First, the Simulink object can be directly inserted into the virtual test bed (VTB) simulation [11], which makes it possible to test the control algorithm with a very detailed system model, and second, an interface layer exits to dSPACE hardware, which allows easy testing of the

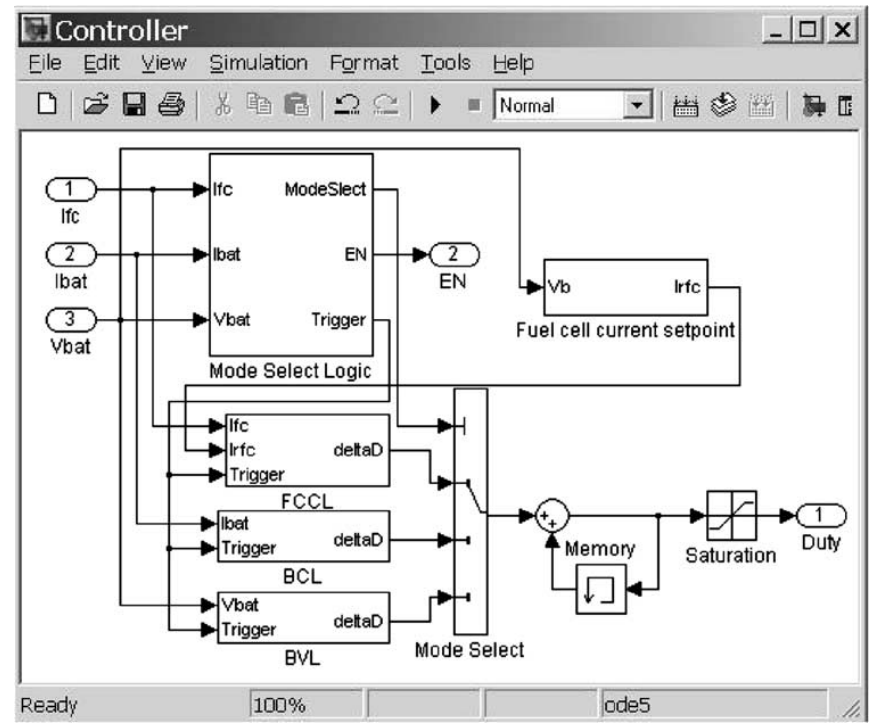

Fig. 5. Simulink implementation of control strategy.

control algorithm on real hardware. The Simulink model of the controller is shown in Fig. 5. The main functional blocks in this Simulink model are fuel cell current setpoint section, regulation mode select section, and compensation loop section.

The fuel cell current setpoint section realizes the strategy illustrated in Fig. 3. The setpoint of the current from the fuel cell stack is calculated based on the measured battery voltage. The regulation mode select section realizes the strategy shown in Fig. 4. The regulation mode is determined according to the current operating conditions (the previous regulation mode and the measured currents and voltages), and the logic of the control strategy. The compensation loop section is used to compute the duty cycle of the power converter according to the selected regulation mode (control objective). A proportional-integral approach is used to regulate the currents and voltages. In order to reduce the voltage or current transients that may occur when the regulation mode is changed, the control scheme consists of a feed-forward term (implemented by the duty cycle at the previous sample interval) plus the proportional and integral terms of the errors of the currents or voltage. The proportional and integral terms of the errors are actually compensating the change of the duty cycle $(\Delta d)$ at the current step. Whenever the regulation mode is changed, each integrator is reset to avoid unusual current or voltage transients at the time of mode change. The current and voltage regulations are formulated in (6)-(8)

$$
\begin{aligned}
& d=d_{\mathrm{old}}+k_{\mathrm{pifc}}\left(I_{\mathrm{rfc}}-I_{\mathrm{fc}}\right)+k_{\mathrm{iifc}} \int\left(I_{\mathrm{rfc}}-I_{\mathrm{fc}}\right) d t \\
& d=d_{\mathrm{old}}+k_{\mathrm{pi}}\left(I_{r b}-I_{b}\right)+k_{\mathrm{ii}} \int\left(I_{r b}-I_{b}\right) d t \\
& d=d_{\mathrm{old}}+k_{\mathrm{pv}}\left(V_{r b}-V_{b}\right)+k_{\mathrm{iv}} \int\left(V_{r b}-V_{b}\right) d t
\end{aligned}
$$

where $I_{\mathrm{fc}}$ is the sampled current from the fuel cell stack; $V_{b}$ the is the sampled voltage of the battery; $I_{b}$ is the sampled current to the battery; $d$ and $d_{\text {old }}$ are the the present and previous duty 


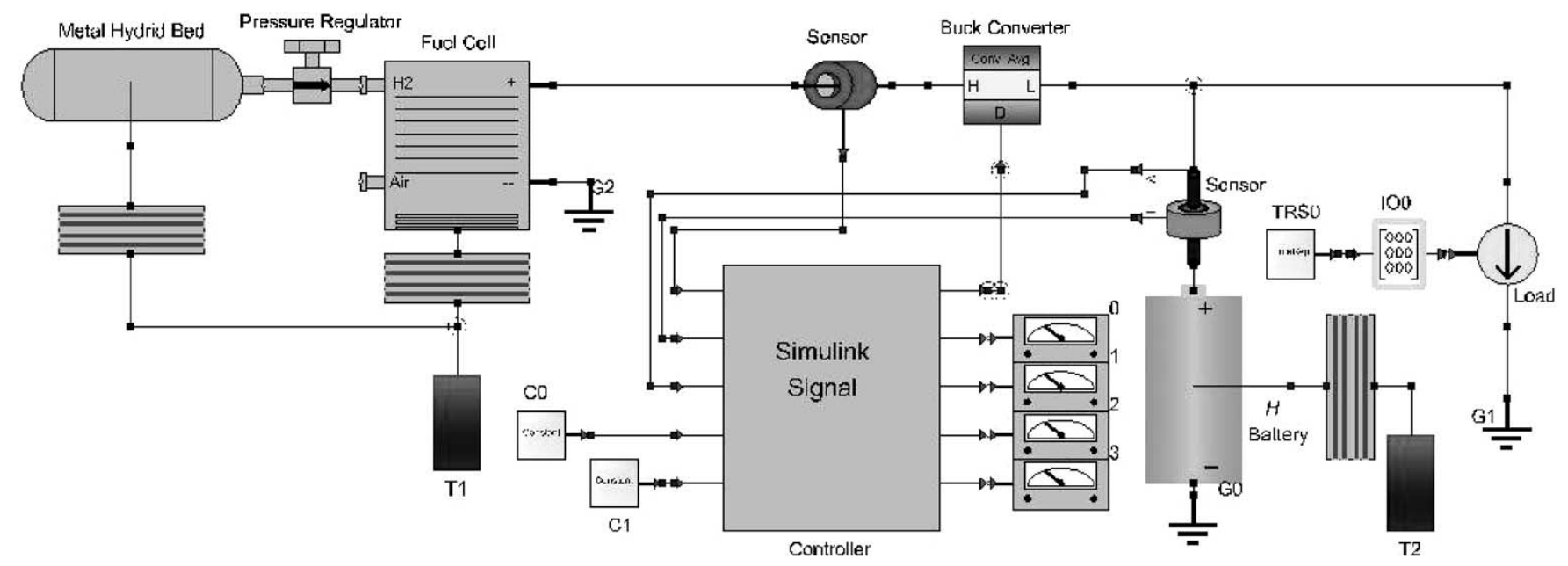

Fig. 6. VTB schematic view of the hybrid fuel cell/battery power source.

cycles used to control the buck converter, respectively; $I_{\mathrm{rfc}}, V_{r b}$, and $I_{r b}$ are the limits for the fuel cell current, battery voltage, and battery charging current, respectively; and $k_{\mathrm{pifc}}, k_{\mathrm{ifc}}, k_{\mathrm{pi}}, k_{\mathrm{ii}}$, and $k_{\mathrm{pv}}, k_{\mathrm{iv}}$ are proportional and integral gains for the fuel cell current, battery current, and battery voltage, respectively.

\section{Simulation Results}

Simulation studies are first conducted in the VTB to investigate the performances of the adaptive control strategy. Configuration I of the hybrid power source is studied here as an example. (The same simulation was done for Configuration II, but is not described here.) Fig. 6 shows the VTB schematic view of the system shown in Fig. 1 (Configuration I). A 25cell PEM fuel cell stack is the main power source. A metal hydride bed is connected to the fuel cell through a pressure regulator to supply hydrogen at $1.0 \mathrm{~atm}\left(1.0133 \times 10^{5} \mathrm{~Pa}\right)$ constant pressure. Both the fuel cell and the metal hydride bed are configured to independently exchange heat with the ambient environment. The battery is configured as four cells in series and two strings in parallel. The capacity of each cell is $1.4 \mathrm{Ah}$. The initial state-of-charge of the battery is 0.5 . The battery also exchanges heat with the ambient. The load periodically draws a random pulse current. The period is $600 \mathrm{~s}$, and during each cycle, the current varies widely between 6 and $0.1 \mathrm{~A}$, as shown in Fig. 7.

The Simulink model of the controller, shown in Fig. 5, is embedded into the VTB simulation. The fuel cell current setpoint is changed according to the strategy described in Fig. 3, where $\mathrm{v}_{1}=14.75 \mathrm{~V}, \mathrm{v}_{2}=16.25 \mathrm{~V}, \mathrm{I}_{\mathrm{mpp}}=2 \mathrm{~A}$, and $\mathrm{I}_{\text {meff }}=0.5$ A. The limit of the battery charging current is set at $1.6 \mathrm{~A}$, according to the maximum safe charging rate of the battery. The limit of the battery voltage is set to $16.6 \mathrm{~V}$. Table I lists the gains for current and voltage regulations in the control algorithm shown in (6)-(8). The simulation is run for $6000 \mathrm{~s}$, and the simulation results are shown in Figs. 8-13. Fig. 8 shows the currents from the fuel cell stack, from the battery and to the load. Fig. 9 shows the voltages of the fuel cell stack and the battery. These currents and voltage during the first cycle are plotted in

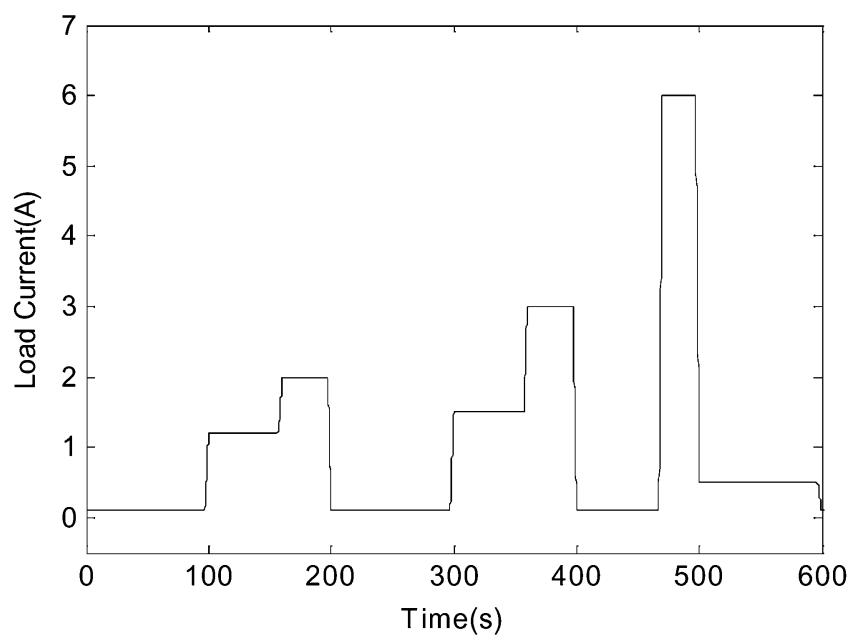

Fig. 7. Profile of the current drawn by the load during each cycle.

TABLE I

GAINS FOR CURRENT AND VOLTAGE REgULATIONS

\begin{tabular}{c|c|c|c|c|c}
\hline$k_{p i f c}$ & $k_{i j f c}$ & $k_{i i}$ & $k_{p i}$ & $k_{p v}$ & $k_{i v}$ \\
\hline 0.02 & $2.0 \times 10^{-6}$ & 0.02 & $2.0 \times 10^{-6}$ & 0.01 & $1.0 \times 10^{-6}$ \\
\hline
\end{tabular}

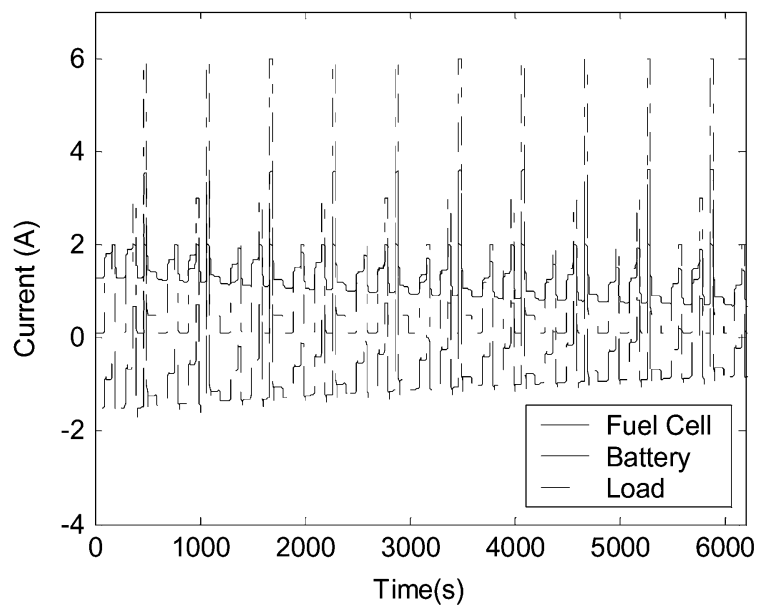

Fig. 8. Currents from the fuel cell stack, from the battery and to the load. 


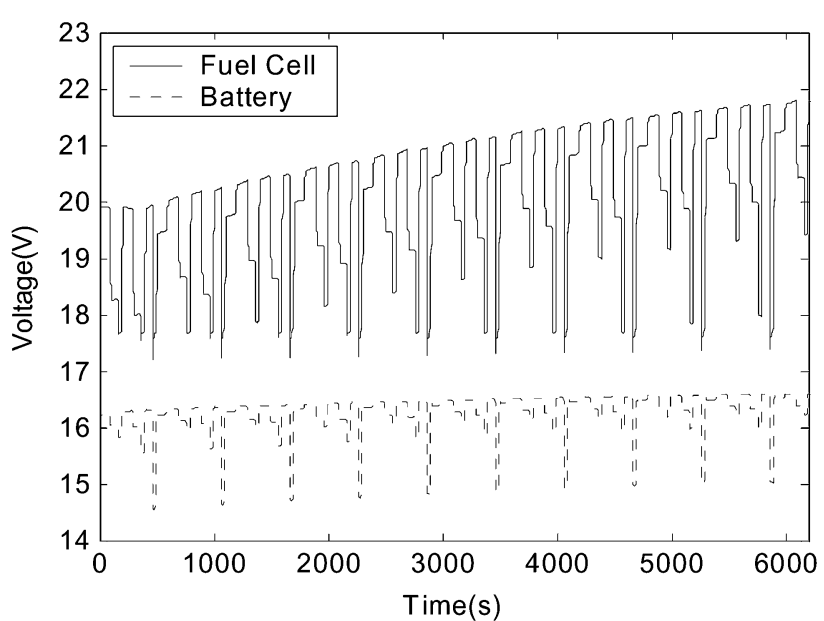

Fig. 9. Voltages of the fuel cell and the battery.

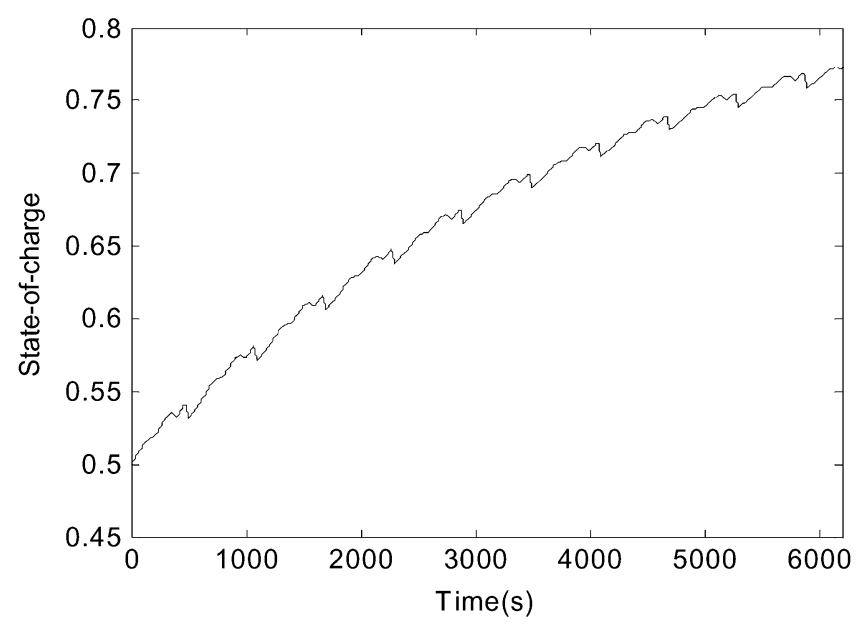

Fig. 10. Calculated state-of-charge of the battery.

Figs. 12 and 13. The calculated state-of-charge of the battery is plotted in Fig. 10. Fig. 11 displays the change of regulation mode.

Initially, when the load draws a very low current of $0.1 \mathrm{~A}$, the fuel cell current is about $1.3 \mathrm{~A}$, providing a high current to charge the battery. Almost immediately, the charging current of the battery reaches the current limit $(1.6 \mathrm{~A})$, and then battery current limit (BCL) mode applies (see Fig. 11) and the charging current is regulated at $1.6 \mathrm{~A}$ (Fig. 12). When the load current increases to $1.2 \mathrm{~A}$ at $100 \mathrm{~s}$, the fuel cell current exceeds the previous setpoint, and then fuel cell current limit (FCCL) mode applies (Fig. 11). At this mode, the charging current of the battery declines due to the load change and the battery terminal voltage decreases accordingly (Fig. 13). The controller then sets a higher fuel cell current $(1.8 \mathrm{~A})$ according to the battery voltage. When the load current increases to $2 \mathrm{~A}$ at $160 \mathrm{~s}$, the battery voltage declines to $15.8 \mathrm{~V}$ due to the decrease of the charging current and then the controller increases the fuel cell current setpoint to $2 \mathrm{~A}$. When the load requirement decreases at $200 \mathrm{~s}, \mathrm{BCL}$ mode applies again. Afterward, the fuel cell current setpoint continues to vary with the changes of the load demand and the battery state. It is important to note that when the load

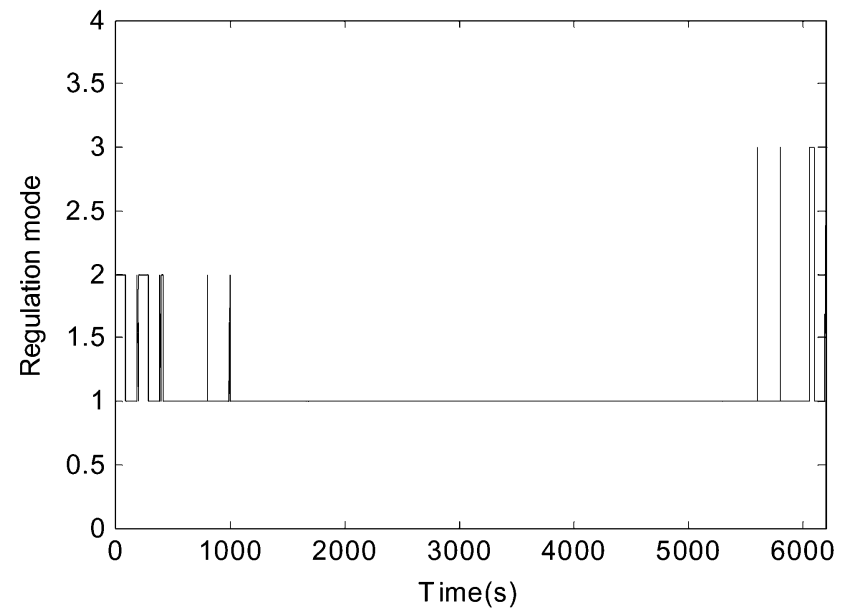

Fig. 11. Change of the regulation mode (1: FCCL, 2: BCL, 3: BVL).

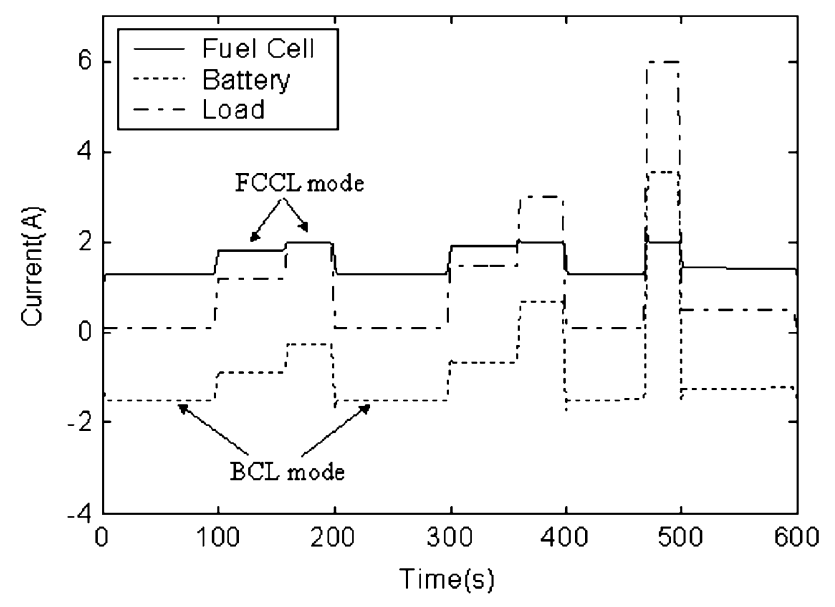

Fig. 12. Currents of the fuel cell, battery, and load during the first cycle.

draws 6 A (or even 3 A) current, the fuel cell cannot supply sufficient current to the load and then the battery is discharged, resulting in the sudden drop of the terminal voltage (below the setpoint of $v_{2}$ ). The setpoint of the fuel cell current is then increased to $2.2 \mathrm{~A}$ (Fig. 12), corresponding to the maximum power point of the fuel cell stack.

During some cycles, when the battery voltage reaches its limit $(16.6 \mathrm{~V})$, for example, at $5600 \mathrm{~s}$, the battery voltage limit (BVL) mode applies (see Fig. 11) and the battery voltage is regulated at $16.6 \mathrm{~V}$ (see Fig. 9). The state-of-charge of the battery, as shown in Fig. 10, increases when the battery is charged and decreases when discharged. During each cycle, the net increase of the state-of-charge is positive. This is because the average power of the load is less than the average output power of the fuel cell, and the net input power to the battery is positive. However, the net increase of the state-of-charge slows down eventually to zero over time, because the fuel cell supplies less power than initially under the same load cycle when the battery voltage increases to the limit. Fig. 11 shows that the regulation mode is selected correctly according to the battery charge level and the load characteristics. Simulation results show that the fuel cell current, battery current, and battery voltage are regulated properly and 


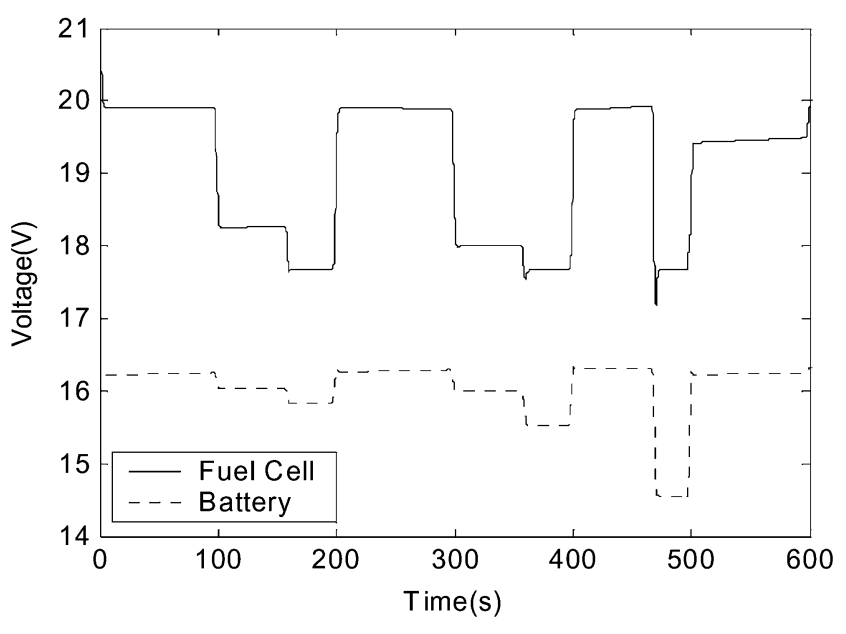

Fig. 13. Voltage of the fuel cell and the battery during the first cycle.

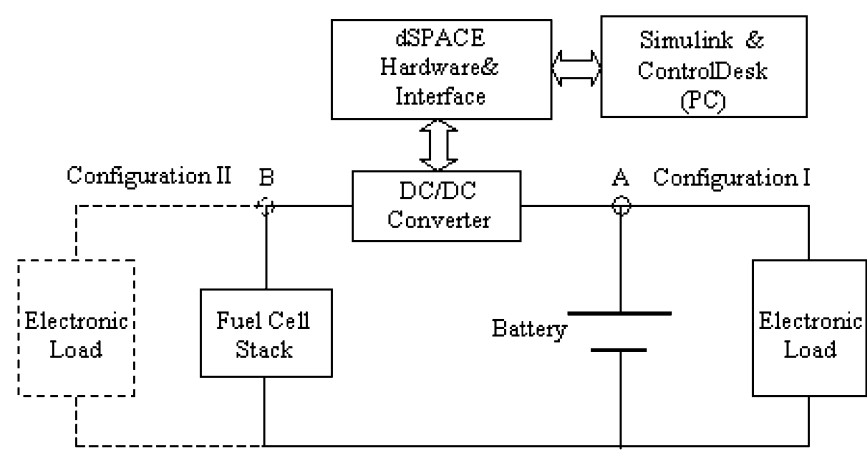

Fig. 14. Block diagram of the experiment platform.

that the power of the active hybrid is reasonably shared between the two sources with the adaptive control strategy.

\section{EXPERIMENTAL VALIDATION}

A prototype of the hybrid power source has been built using an H-Power D35 PEM fuel cell stack and 8 Sony 18650 lithiumion cells to validate the adaptive control strategy. Fig. 14 shows a block diagram of the experimental platform. The hybrid power source has two output terminals (A and B) with different terminal voltages. Connecting the load to the battery at node $\mathrm{A}$, or to the fuel cell at node $\mathrm{B}$, results in two different configurations (I and II, respectively). The power converter is controlled by a dSPACE controller board (model DS1103 PPC). The currents and voltages of the fuel cell stack and the battery are monitored and fed into the controller. The controller calculates the duty cycle of the power converter and sends the duty commands to the hardware.

The fuel cell stack has a nominal power capacity of $35 \mathrm{~W}$ and a nominal open circuit voltage of $24 \mathrm{~V}$. Lithium-ion cells are connected as four cells in series and two such strings in parallel. The nominal capacity of each cell is $1.4 \mathrm{Ah}$. The electronic load periodically draws the same current as for the simulation, as identified in Fig. 7. Table II describes the major components used. Tests are conducted on two different configurations to validate the adaptive control strategy and to demonstrate the
TABLE II

COMPONENTS USED IN THE HYBRID POWER SOURCE

\begin{tabular}{c|c|c}
\hline Component & Description & Comments \\
\hline PEM Fuel Cell Stack & H Power DS35 & 25 cells in series \\
\hline Battery Pack & SonyUS18650 & $\begin{array}{c}4 \times 2 \text { cells (series by } \\
\text { parallel connections) }\end{array}$ \\
\hline Load & Chroma 6310 & Digitally controllable \\
\hline DC/DC Converter & Buck Converter & $92 \%$ efficiency \\
\hline Controller & dSPACE DS1103 & $\begin{array}{c}\text { Controller hardware } \\
\text { plus interface }\end{array}$ \\
\hline
\end{tabular}

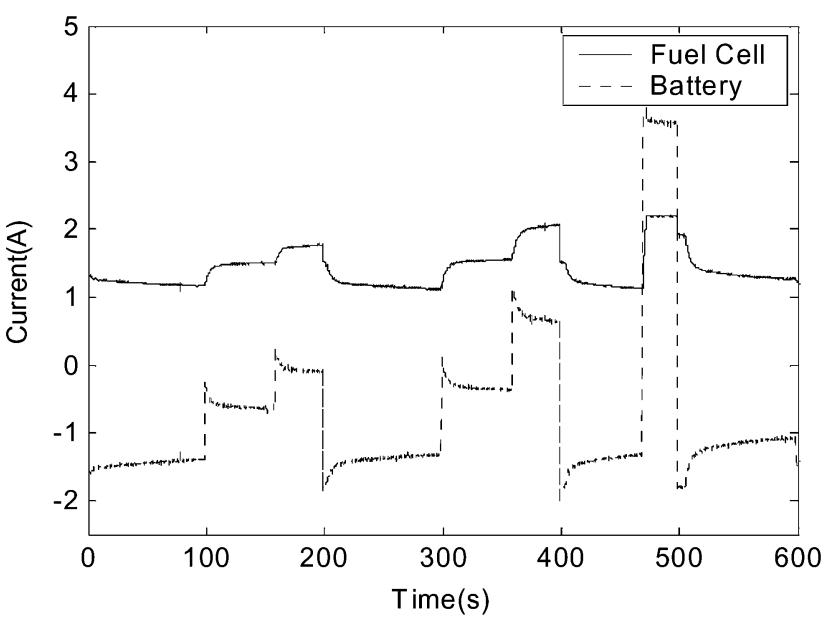

Fig. 15. Currents from the fuel cell and the battery in Configuration I.

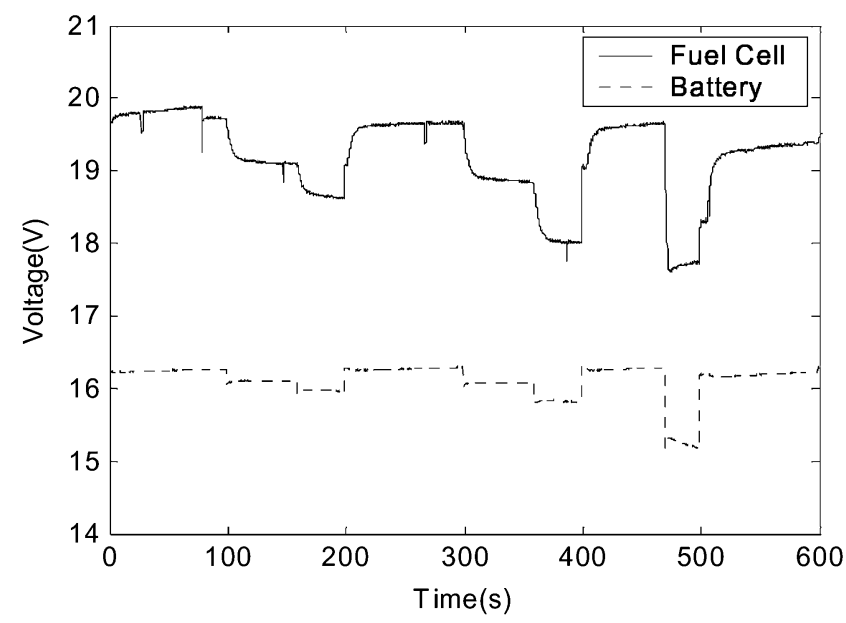

Fig. 16. Voltages of the fuel cell and the battery in Configuration I (Top: fuel cell voltage, Bottom: battery voltage).

generality of the control system. The control algorithm developed in Simulink is compiled, and downloaded to the dSPACE controller board to control the real hardware. The parameters of the controller are the same as for the simulation. Experimental results are shown in Figs. 15-18.

Figs. 15 and 16 show the currents and voltages of the fuel cell and the battery, respectively, during the first cycle in Configuration I. Initially, when the load draws $0.1 \mathrm{~A}$ current, most of the fuel cell current (about 1.3 A) is used to charge the battery, and the charging current reaches the current limit. Then BCL mode applies and the charging current is regulated at $1.6 \mathrm{~A}$. When the load current increases to $1.2 \mathrm{~A}$, the fuel cell current 


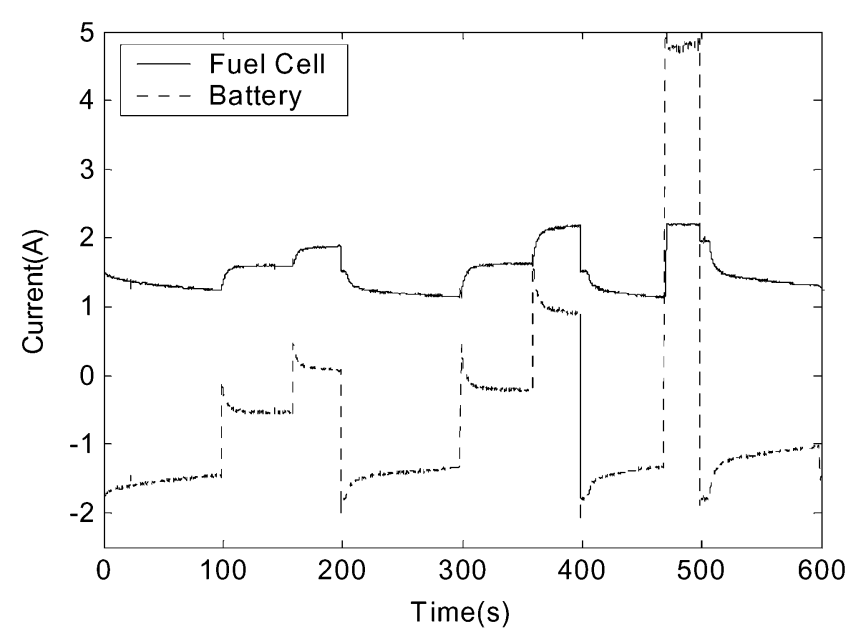

Fig. 17. Currents from the fuel cell and the battery in Configuration II.

exceeds the previous setpoint; then FCCL mode applies, and the charging current of the battery declines due to the load change. It is shown in Fig. 16 that the battery terminal voltage decreases accordingly. The controller then sets about 1.8 A fuel cell current according to the decrease of the battery voltage and the fuel cell voltage decreases (Fig. 16). When the load current increases to $2 \mathrm{~A}$, the battery voltage declines due to the decrease of the charging current, and then the controller increases the fuel cell current setpoint to approximately $2 \mathrm{~A}$, which actually compensates the increase of the load demand. When the load demand becomes low, BCL mode applies again, and is then followed by FCCL mode. Later, the fuel cell current setpoint continues to vary with the changes of the load demand and the battery voltage.

When the load draws 3 A or 6 A current, the fuel cell cannot provide sufficient power to the load and then the battery is discharged, causing the terminal voltage to drop below the setpoint of $v_{2}$. The setpoint of the fuel cell current is then increased to 2.2 A maximum current (Fig. 12), corresponding to the maximum power point of the fuel cell stack. This adjustment is very helpful because the fuel cell supplies more power when the load is very high. It is worthwhile to note that when the load changes from a very high current to a lower current, the controller first limits the battery current, and then the fuel cell current. This is because at these times the battery changes from discharging to charging or from low current charging to high current charging and it takes time for the battery voltage to recover. When these changes take place, the controller gives a higher fuel cell current setpoint than the steady state, which causes the battery current to reach its limit. This is not clearly observed in the simulation because the simulation model does not capture the very detailed transients of the battery voltage. Another reason for this difference is that a low pass filter was used in the experiments, which caused the measured signals to delay. It is seen from the experimental results that the fuel cell current and the battery current are regulated properly.

The currents and voltages of the fuel cell and the battery during the first cycle in Configuration II are shown in Figs. 17

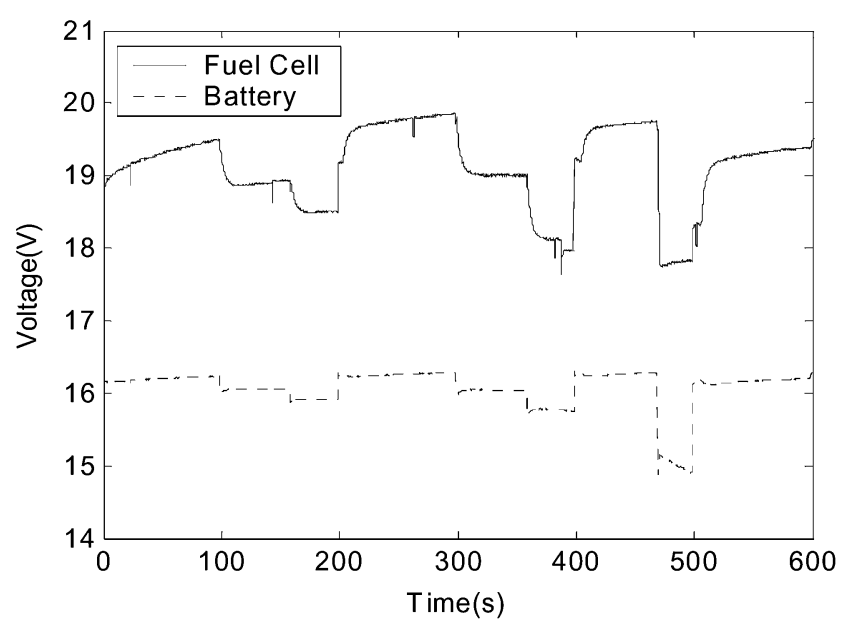

Fig. 18. Voltages of the fuel cell and the battery in Configuration II (Top: fuel cell voltage, Bottom: battery voltage).

and 18, respectively. During the operation, the fuel cell current setpoint continues to vary with the changes of the load demand and the battery voltage. Initially, when the load is low, BCL mode applies and the charging current is regulated at $1.6 \mathrm{~A}$. When the load current increases to 1.2 A, FCCL mode applies, and the fuel cell current is regulated at around $1.8 \mathrm{~A}$. The charging current of the battery declines and the terminal voltage decreases. When the load current becomes very high, the controller increases the fuel cell current setpoint to compensate the increase of the load demand. When the load draws peak power, the fuel cell current is set at $2.2 \mathrm{~A}$ maximum current, and the fuel cell stack outputs maximum power available. It is also seen that the fuel cell current and the battery current are regulated properly in Configuration II.

Experimental results validate that the same control strategy is applicable to different configurations, and has great flexibility and generality. Experimental results also show that the power in the both configurations of active hybrids is reasonably shared between two sources with the adaptive control strategy. It is found from the experimental results that the efficiency of the hybrid power source is higher than $92 \%$, which makes the hybrid power source really attractive. Furthermore, another significant observation is that the fuel cell current responds more slowly in Configuration II than in Configuration I when the load changes rapidly. This is because in Configuration II, the fuel cell is closer to the load and it takes time for the inductor in the power converter to change the current when the battery is charged or discharged. But this time delay is very short (in milliseconds), and it does not affect the pulsed operation of the power source (in seconds) significantly.

\section{CONCLUSION}

This paper presents an adaptive control strategy for active power sharing in the hybrid power source. This control strategy can adjust the output current setpoint of the fuel cell according to the state-of-charge (or voltage) of the battery, and is applicable in two topologies of active fuel cell/battery hybrids. The control 
strategy is implemented in Simulink and then tested under arbitrary load conditions through simulation and experiments. Simulation and experimental results show that the adaptive control strategy is able to adjust the fuel cell output current to adapt to the charge state of the battery and distribute the electrical power between them appropriately. Experiments demonstrate the generality of the adaptive control strategy. Experimental results validate the simulation models.

\section{REFERENCES}

[1] T. B. Atwater, P. J. Cygan, and F. C. Leung, "Man portable power needs of the 21st century: I. Applications for the dismounted soldier. II. Enhanced capabilities through the use of hybrid power sources," J. Power Sources, vol. 91, no. 1, pp. 27-36, Nov. 2000.

[2] R. F. Nelson, "Power requirements for batteries in hybrid electric vehicles," J. Power Sources, vol. 91, no. 1, pp. 2-26, Nov. 2000.

[3] A. Heinzel, C. Hebling, M. Müller, M. Zedda, and C. Müller, "Fuel cells for low power applications," J. Power Sources, vol. 105, no. 2, pp. 148153, Mar. 2002.

[4] P. B. Jones, J. B. Lakeman, G. O. Mepsted, and J. M. Moore, "A hybrid power source for pulse power applications," J. Power Sources, vol. 80, no. 1-2, pp. 242-247, Jul. 1999.

[5] L. Gao, Z. Jiang, and R. A. Dougal, "An actively controlled fuel cell/battery hybrid to meet pulsed power demands," J. Power Sources, vol. 130, no. 2, pp. 202-207, May 2004.

[6] Z. Jiang, L. Gao, and R. A. Dougal, "Design and experimental tests of control strategies for active hybrid fuel cell/battery power sources," J. Power Sources, vol. 130, no. 1, pp. 163-171, May 2004.

[7] C. E. Holland, J. W. Weidner, R. A. Dougal, and R. E. White, "Experimental characterization of hybrid power systems under pulse current loads," J. Power Sources, vol. 109, no. 1, pp. 32-37, Jun. 2002.

[8] J. Kim, S. Lee, and S. Srinivasan, "Modeling of proton exchange membrane fuel cell performance with an empirical equation," J. Electrochem. Soc., vol. 142, no. 8, pp. 2670-2674, Aug. 1995.

[9] B. Thorstensen, "A parametric study of fuel cell system efficiency under full and part load operation," J. Power Sources, vol. 92, no. 1-2, pp. 9-16, Jan. 2001.

[10] Z. Jiang and R. Dougal, "Real-time strategy for active power sharing in a fuel cell powered battery charging station," J. Power Sources, vol. 142, no. 1-2, pp. 253-263, Mar. 2005.

[11] T. Lovett, A. Monti, E. Santi, and R. Dougal, "A multilanguage environment for interactive simulation and development of controls for power electronics," in Proc. IEEE 32nd Annu. Power Electronics Specialists Conf., vol. 3, 2001, pp. 1725-1729.

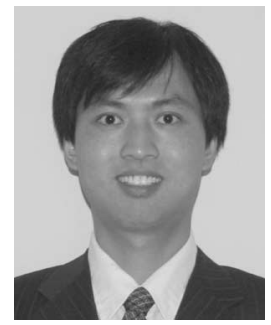

Zhenhua Jiang (S'01-M'03) received the B.Sc. and M.Sc. degrees from Huazhong University of Science and Technology, Wuhan, China, in 1997 and 2000, respectively, and the Ph.D. degree from the University of South Carolina, Columbia, in 2003, all in electrical engineering.

He has been an Assistant Professor in the Department of Electrical and Computer Engineering at the University of Miami, Coral Gables, FL, since 2006. From 2005 to 2006, he was an Assistant Professor with the University of New Orleans, LA. From 2003 to 2005, he was a Postdoctoral Fellow at the University of South Carolina, Columbia. His current research interests include renewable and alternative energy systems, integration of distributed energy resources, modeling and control of microgrids, intelligent control systems, hybrid advanced power sources and systems, applications of power electronics in utility power systems, agent technology, and modeling and simulation of interdisciplinary systems.

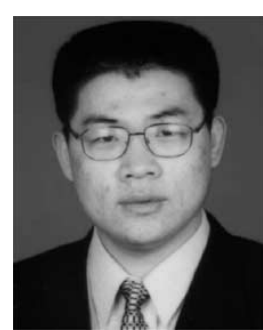

Lijun Gao (M'04) received the Ph.D. degree in electrical engineering from the University of South Carolina, Columbia, in 2003.

His current research interests include design and control of advanced hybrid power sources and systems; modeling; and simulation of hybrid electric vehicles (HEVs).

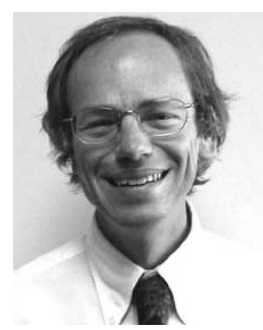

Roger A. Dougal (S'74-M'78-SM'94) received the $\mathrm{Ph} . \mathrm{D}$. degree in electrical engineering from Texas Tech University, Lubbock, in 1983.

$\mathrm{He}$ joined the faculty at the University of South Carolina in 1983. He is Director of the Virtual Test Bed (VTB) project, a multidisciplinary, multiuniversity effort to develop a comprehensive simulation and virtual prototyping environment for advanced power sources and systems, integrating power electronics, electromechanics, electrochemistry, and controls into a common testbed. The VTB is unique in allowing the simulation of multidisciplinary systems by importing models from disciplinespecific source languages to a common workspace. In addition to modeling and simulation, his expertise includes power electronics, physical electronics, and electrochemical power sources.

Dr. Dougal received the Samuel Litman Distinguished Professor of Engineering award, and has been honored as a Carolina Research Professor. 